\title{
Comparing Balint Groups as Face-to-face and as Online Events
}

\author{
Mario Scheib*, Sophie-Charlotte Adler \\ Instituto Dr. Scheib, Clinica Luz, Palma de Mallorca, Spain \\ Email address: \\ dr.scheib@psychosomatik.com (Mario S.), sophie.adler@psychosomatik.com (Sophie-Charlotte A.) \\ ${ }^{*}$ Corresponding author
}

\section{To cite this article:}

Mario Scheib, Sophie-Charlotte Adler. Comparing Balint Groups as Face-to-face and as Online Events. Science Journal of Education. Vol. 9, No. 2, 2021, pp. 69-72. doi: 10.11648/j.sjedu.20210902.18

Received: March 15, 2021; Accepted: April 19, 2021; Published: April 26, 2021

\begin{abstract}
Due to the Coronavirus pandemic, many medical training and further education events have been converted to online seminars. This raises the question of whether the same quality outcome can be achieved with this type of event, as with face-to-face events. This is particularly true for Balint groups, where a high degree of interaction takes place and non-verbal communication between the group participants also plays a big part. Balint groups as face-to-face events have an increased risk of infection for the participants and are no longer approved by many employers to avoid staff shortages due to doctors falling ill. In the anonymous survey of participants from different groups, the evaluation by the on-line participants actually showed advantages, compared to a face-to-face event. The online format even leads to doctors who would normally not be able to attend a Balint group now taking advantage of this training. Balint groups can therefore be a support in doctors' work, especially in situations of great workload - as in the current pandemic. Disadvantages of this format are clearly outweighed by the advantages. The results suggest that, online Balint groups and face-to-face events should continue to be offered simultaneously and the outcomes should be further investigated.
\end{abstract}

Keywords: Balint Groups, Online Seminars, Comparison, Corona, Covid 19

\section{Introduction}

The Coronavirus pandemic, the risk of infection and the resulting travel restrictions meant, that many face-to-face medical training courses could no longer be held as planned. Out of necessity, within a few days, all events had to be switched to online seminars, so-called "webinars", which was surprisingly successful. The interactive online seminars on basic psychosomatic care were rated just as well as the live events, and in some cases even slightly better.

In Germany, participation in Balint groups is compulsory within the framework of specialist training in general medicine, gynecology and pain management therapy [1], as well as for improved billing possibilities in the Practice in a wide range of medical specialties. As opposed to other countries, many of the group participants in Germany, lack in fundamental motivation required to engage.

On the other hand, the current pandemic is leading to a higher physical and psychological workload for many physicians, with the risk of becoming infected themselves during training events.

Several Balint group leaders reported positive experiences. Nease et al. [2] reported about an international Balint-group and confirms that: "Quarterly survey responses were more positive reflecting agreement with outcomes seen from inperson Balint groups." In our study, we surveyed participants from different Balint groups, with three different group leaders in the Psychosomatic Primary Care Curriculum.

Dehkordi et al. [3] reported positively about Balint groups during the Corona pandemic in Iran. Healthcare professionals were working under extreme psychosocial stressors and could only attend online due to infection risks.

Good coping mechanisms can help to reduce work-related stress. Koppe et al. [4] reported the positive effects of online balint groups for doctors as they were able to improve their coping strategies.

The Balint Society of Australia \& New Zealand offers regularly online balint groups [5] similar to the American Balint Society [6].

In July 2020 the first International Balint Round table 
started with people from all around the world to discuss online [7].

Furthermore there is a web project called "Balint 2.0 Ambassadors" supported by the Balint Federation [8].

\section{Investigation}

\subsection{Participants}

128 course participants took part in our survey on online Balint groups, via Survey Monkey. Some of them had already taken part in face-to-face Balint groups with the same leaders, others had only taken part in online groups. When comparing face-to-face Balint groups with online groups, the online groups scored 4.9 out of a possible 5 stars, which is significantly better than the conventional groups. $32 \%$ of the participants rated both groups as equally helpful and 39\% rated online groups as more helpful than the face-to-face events. $96 \%$ said they would continue to participate in online Balint groups, even when the current pandemic restrictions are eventually lifted.

\subsection{Evaluation of Helpfulness of Online Balint Groups}

When asked how helpful the participants consider online Balint groups via video conferencing, 89\% ( $\mathrm{N}=110)$ answered "very helpful".

The advantages of the online Balint groups, outlined by the participants were as follows (Figure 1):

More flexibility, practicality and ability to plan

No need to travel, not being tied to a specific location

Time efficiency

Cost efficiency

Family friendliness

Increased personal well-being through better integration into everyday life and less stress

Improved ability to concentrate

Availability in times of crisis and in rural regions

Safety and security

Easily accessible

Environmentally friendly

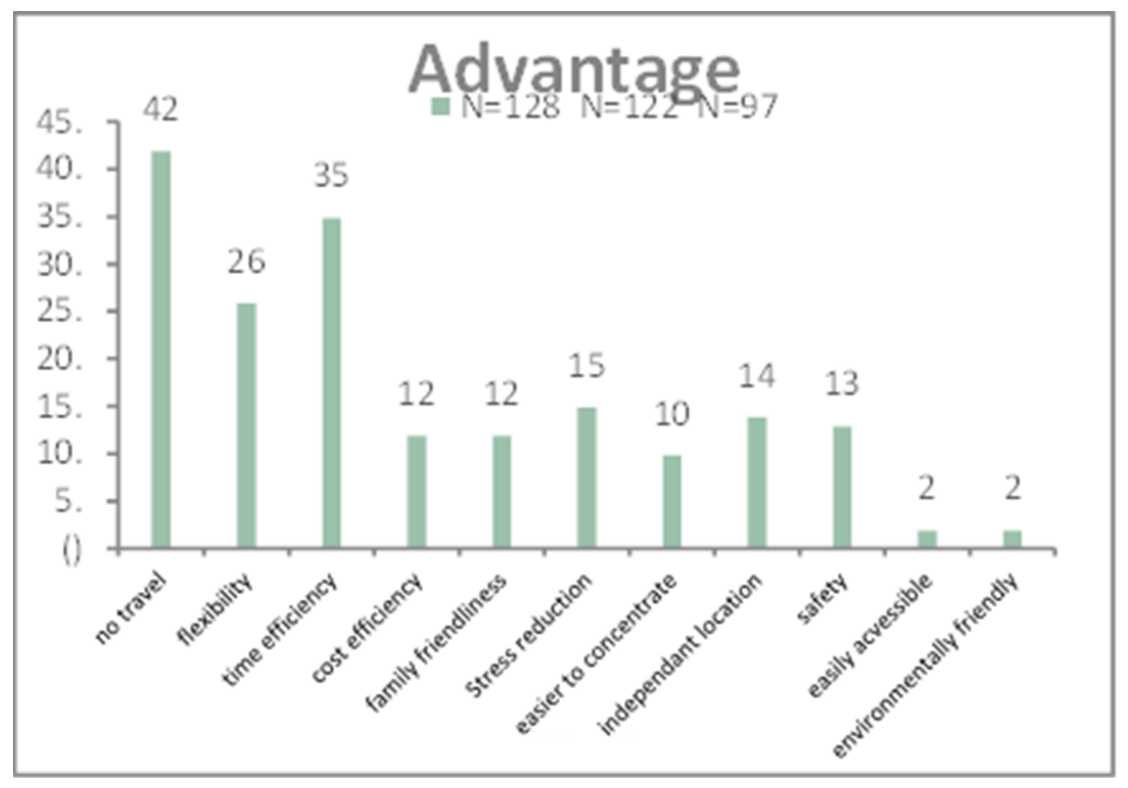

Figure 1. Advantage of online Balint gropus.

These figures clearly show that the doctors experience a great advantage by not having to actively travel to face-toface events. "Only the online Balint groups have given me the opportunity to participate regularly, which has definitely enriched and improved my daily work. Due to the long travel distance and the long shifts I work, it is absolutely impossible for me to attend face-to-face events regularly. Thank you for this great opportunity to improve my daily work in a manageable time-frame. I hope and wish very much, that there will also be online Balint groups in the future".

The participants state, that they could concentrate better from home than at face-to-face events. Participants feel comfortable, relaxed and safe in their familiar environment. "The home setting lets you talk about emotions more openly. This is especially suitable for rather shy participants." The majority of participants report a better or at least the same "learning efficiency", precisely because they can be relaxed in their own homes without the need to travel back and forth. Many participants report that they would be more confident to actively participate in group interactions compared to faceto-face events, as they feel more anonymous and comfortable. "During an online event, one is more likely to bring up the courage to discuss problematic things, compared to when they have a lot of people sitting directly opposite them and staring at them". At the same time, there is a greater openness among the participants because they are able to take part in Balint groups from anywhere in Germany.

Especially the time flexibility and cost savings are of great importance for the doctors. "The online event saves me 2 hours of travel each way. The fact that it is a discussion 
group, means that it can take place just as effectively as a video conference, without any loss in quality".

Furthermore, many doctors see an advantage in the online group, as the risk of infection (Coronavirus), is non-existent. Many also emphasized that an approach in this format is also very environmentally friendly. "If you are very busy at work and give great importance to environmental protection, then this online format is ideal!"

It is clear to see that there is a greater compatibility between work and home-life, which as a result leads to the doctors feeling more relaxed and leads to an increase in motivation among them. "For parents, there should be the possibility to continue participating online. This is much easier to integrate into everyday life and thus relieves a lot of pressure! The online training Balint groups, have worked very well and the implementation is absolutely contemporary! From my point of view, it would not make sense to go back in time".

Statements such as the following are frequently found in the comments of the respondents: "The online Balint groups are just as good as the face-to-face events and were well organised and very instructive. I would like the online offer to continue in the future. You also save a lot of time and money in terms of travel and hotel costs." Consistently, there seems to be a great advocacy of the online format, which can be illustrated by statements such as the following: "In my surgical phase, I would have urgently wished for Balint groups to enable me to process some tragic cases, but this was not possible while spending 70 hours a week in the clinic. I think there would be an increase in voluntary participation in Balint groups, (without them being compulsory for certain further training), if they could be conducted online in the future. That way, some colleagues could work through situations that are "bothering" them."

\subsection{Evaluation of the Disadvantages of Online Balint Groups}

When asked what disadvantages the participants see in participating in an online Balint group, the following distribution emerged (Figure 2).

A majority of $35 \%$ see no disadvantages at all in the new format.

At first, the new format was unfamiliar and non-verbal communication was limited.

Many participants miss the social exchange with colleagues during their breaks. This makes it more difficult to make new contacts and exchange knowledge or experiences with different disciplines. This also leads to this format being viewed as somewhat more impersonal / anonymous; "Less group participation", "No teamwork". In addition, non-verbal behaviour is less perceivable. Some participants also see the online format as an opportunity to "remain more passive".

A further complication of the online format is the dependence on a reliable internet connection. "Dependent on good internet connection - just like you are dependent on clear roads, a functioning car and punctual train connections when you attend face-to-face events". Connection problems can lead to colleagues experiencing difficulties communicating with each other; misunderstandings can occur and the group dynamic could sometimes be interrupted. The same applies to technical problems. "Every now and then there are technical problems, but it's not too bad".

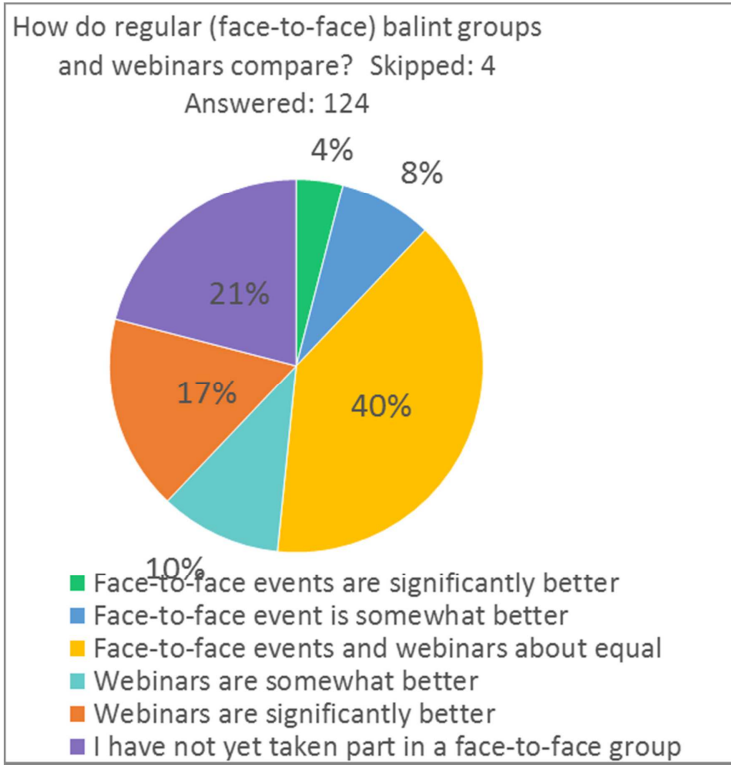

Figure 2. Comparison Online and face-to-face Balint groups.

\section{Comparison of Online Balint Groups and Regular Balint Groups}

\subsection{Percentages of Comparison Between Regular Balint Groups and Online Balint Groups}

Comparison Online Balint groups and regular Balint groups

$40 \%$ of the participants rated the online events to be equally as good as the face-to-face events.

$4 \%$ rated the face-to-face events as "significantly better" and $8 \%$ as "somewhat better". In comparison, $17 \%$ consider the online group to be "significantly better" and 10\% deamed it "somewhat better". (Figure 3: skipped: 4, answered: 124)

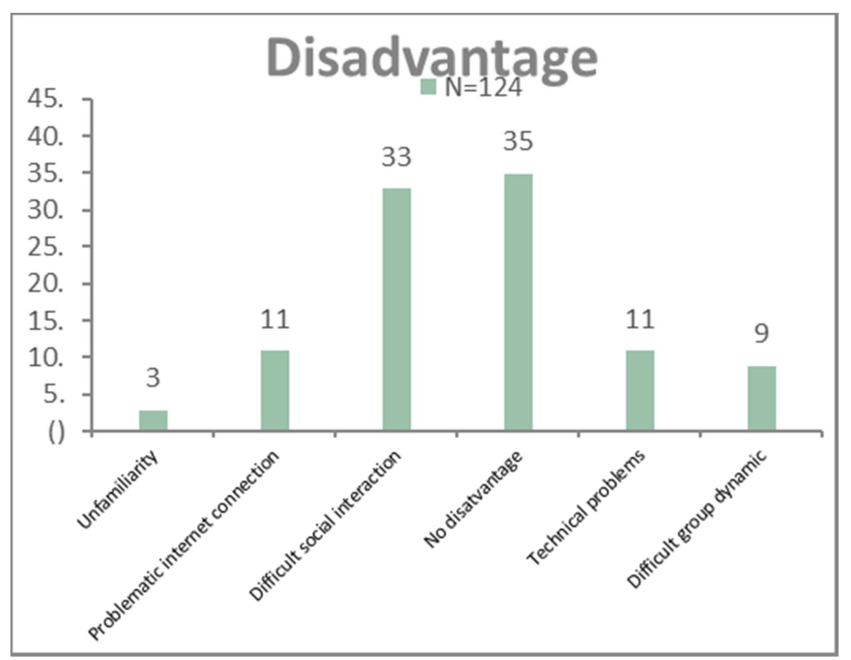

Figure 3. Disadvantage of Online Balint gropus. 


\subsection{Evaluation of Future Participation}

$91 \%$ of the physicians who were surveyed would still participate in online Balint groups, even after the pandemicrelated contact restrictions are lifted. (Figure 4: Skipped: 0, Answered 128)

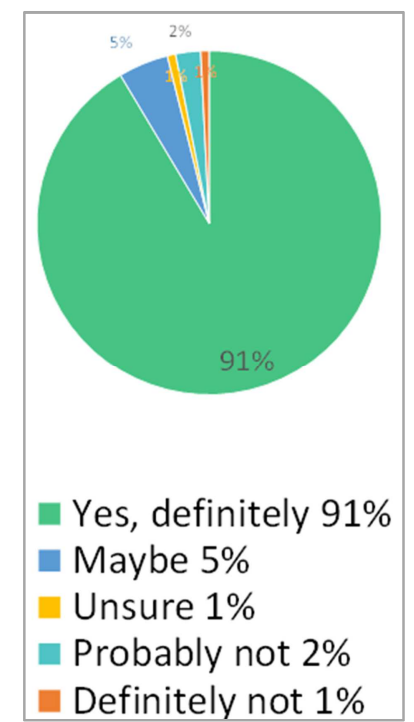

Figure 4. Repeated participation in online Balint groups.

\section{Comments of the Participants}

Finally, some more examples of the participants' comments:

(1) "Online Balint groups/training are something good that came from the Coronavirus crisis. In this day and age training should be offered online whenever possible".

(2) "There are only benefits to it and as a result, more doctors would probably take part and benefit from it".

(3) "I was surprised that my expectations were exceeded".

(4) "I was really relieved to hear of the availability of an online Balint group during the pandemic".

(5) "The medical associations should please also take into account, that doctors do not have much time besides their job, work overtime, rotating shifts and weekend duty. All this should remain compatible with family commitments, external further training and other private commitments. I have been to several psychiatric clinics, not all of them offer an in-house Balint group. Others make it impossible to participate because they schedule you to work in the A\&E department at the same time. And the external groups according to the Balint Group Society are very regionally dependent, I continuously received bookingcancellations. We should move with the digital times and make it possible for us doctors not to delay our training time unnecessarily. You should be able to choose for yourself whether you prefer online or faceto-face events! I was able to voice my concerns online and did not have the feeling that it was less achievable, or more limited than in a face-to-face group. For me it is equally good and it would be a real shame, if there were soon to be no more online Balint groups".

\section{Conclusion}

In summary, our research confirms the findings of Nease and Dehkodi. Online Balint groups are considered better than, or equal to, face-to-face groups. This suggests that online Balint groups and face-to-face events, should continue to be offered simultaneously and the outcomes should be further investigated. Presumably, this will convince even more colleagues of the advantages of continuing with online Balint group work who currently only participate, due to an obligation within the framework of the further training regulations, or provisions of the KV (Association of Statutory Health Insurance Physicians) and do not continue to participate, after fulfilling the required minimum amount of hours.

Especially in the current pandemic situation, low-threshold and easily accessible support services for physicians appear important. Online Balint groups can make a significant contribution.

\section{References}

[1] Bundesärztekammer (2018): Muster Kursbuch Psychosomatische Grundversorgung.

[2] Donald E Nease, Jr, Albert Lichtenstein, Luis Pinho-Costa, Kyle Hoedebecke (2018) Balint 2.0: A virtual Balint group for doctors around the world.

[3] Mansoureh Kiani Dehkordi, Shahin Sakhi, Shakiba Gholamzad, Mohammad Azizpour and Najmeh Shahini (2020) Online Balint groups in healthcare workers caring for the COVID-19 patients in Iran.

[4] Balint group online - Master class by... | INTERNATIONAL BALINT ROUND TABLE. (n.d.). Retrieved April 15, 2021, from https://balintrt.com/balint-group-online-master-class-by/

[5] Balint groups - The American Balint Society. (n.d.). Retrieved April 15, 2021, from https://www.americanbalintsociety.org/content.aspx?page_id= 22\&club_id $=445043 \&$ module_id $=406070$

[6] Global Family Doctor - WONCA Online. (n.d.). Retrieved April 15, 2021, from https://www.globalfamilydoctor.com/news/balint20.aspx

[7] Koppe, H., van de Mortel, T. F., \& Ahern, C. M. (2016). How effective and acceptable is Web 2.0 Balint group participation for general practitioners and general practitioner registrars in regional Australia? A pilot study. Australian Journal of Rural Health, 24 (1), 16-22. https://doi.org/10.1111/ajr.12212

[8] Online Groups | Balint Society of Australia \& New Zealand. (n.d.). Retrieved April 15, 2021, from https://www.balintaustralianewzealand.org/about/join-a-balintgroup/online-groups/ 